\title{
PROGNOSTIC FACTORS IN ELECTRIC CONVULSIVE THERAPY BY
}

\author{
ROBERT F. HOBSON
}

\author{
From the Bethlem Royal and Maudsley Hospitals, London
}

Although convulsive therapy is used with enthusiasm in many mental illnesses, there is, as yet, a lack of evidence on which to base criteria for the selection of cases. In view of the very definite physical risks and possible harmful psychological effects, it is important that precise indications for the treatment should be determined. The present investigation is an attempt to assess statistically the significance of particular features of the history and clinical state in regard to outcome of treatment, and so to discover valid guides to immediate prognosis.

Broad, discontinuous groupings, such as diagnostic categories, are unsuitable for prognostic purposes, being too ill defined and too widely inclusive. Published results of treatment are difficult to compare and interpret so long as such groups, bearing the same labels, vary to an unknown extent in clinical status. There can seldom be a prognosis of a "disease" in psychiatry and prediction must be based upon the heredity, life history, and presenting symptoms of each individual. For these reasons diagnostic criteria were not used in this investigation, a study being made of the association between defined variables in the clinical picture before treatment and subsequent improvement.

\section{Method}

An analysis was made of 150 cases treated by convulsive therapy as in-patients at the Maudsley Hospital.

Unavoidable selection was due to the special type of case admitted to the Maudsley Hospital, and the local opinion regarding indications for the treatment. As all were voluntary patients, and also selected for teaching purposes, there were few chronically ill or severely disturbed patients and there was a high proportion of cases with uncommon features. Almost all cases were depressed and there was a high incidence of neurotic traits.

The presence or absence of 121 clinical items was recorded for each case, special emphasis being given to detailed and objective observations made

E by reliable relatives and friends, amplified by investigations carried out by psychiatric social workers and information from other social and medical sources. An attempt was made to use clear, unequivocal definitions but in many cases purely objective estimation of items was not possible.

Two ratings of improvement were used, Groups A and B. Group A included those who were either completely free of symptoms or had only slight residual symptoms, which, it was judged, would not interfere with working capacity and be only a slight handicap in social relationships. Those patients in Group B might or might not have shown some improvement but still had marked symptoms, were unfit to resume their normal occupation, and were seriously handicapped socially.

In order to investigate prognostic factors bearing upon the immediate outcome, the cases were classified in the clinical groups two weeks after the course of therapy had finished, and the relative frequency of occurrence of the separate clinical items in each group was evaluated statistically (see Table IV) by means of the phi coefficient correlation method. This coefficient is a measure of association between two variables, an approximation to a true correlation when the data are in discontinuous form (Guildford, 1941), the variables here being the presence or absence of improvement and of a particular clinical item. The clinical groups were not strictly discontinuous but could be considered to be so for the purpose of this investigation, where the data did not permit of very accurate statistical treatment. Corrections for continuity were not made.

\section{Analysis of the Case Material}

In some of the 150 unselected cases, treatment had been discontinued prematurely because of refusal of treatment, the occurrence of complications, or change of diagnosis; 23 such patients were excluded from the final analysis. In the remaining group of 127 cases there was no definite relationship between improvement and the number 
of convulsions given. In this group there were no patients who had received less than six convulsions without clinical improvement. The results of treatment in the selected series of cases are shown in Table I.

TABLE I

RESULTS OF TREATMENT IN THE SELECTED SERIES

\begin{tabular}{l|l|l|l}
\hline & \multicolumn{2}{|c}{ Grade of Clinical Improvement } \\
\cline { 2 - 4 } & A (good) & B (poor) & \multicolumn{1}{|c}{ Total } \\
\hline Number of cases & $78(62 \%)$ & $49(38 \%)$ & $127(100 \%)$ \\
Percentage $\quad .$. & 62 & 38 & 100 \\
\hline
\end{tabular}

The association of individual items with outcome in this selected group was assessed by means of the phi coefficient method, and Table II lists the more positive findings. Significant phi coefficients for 127 cases were \pm 0.17 at the $5 \%$ level, \pm 0.21 at the $2 \%$ level, and \pm 0.23 at the $1 \%$ level. Definitions of the items are listed later.

An attempt was made to devise a means of predicting the immediate outcome by scoring clinical items. The most successful scoring method for this series was derived from Table II and consisted in giving a score of 1 for the absence of a favourable feature and for the presence of an unfavourable one. The scores ranged between 2 and 14 and the distribution of cases is shown in Table III. When a score of 7.5 was taken as an index of social recovery, 27 cases $(21 \cdot 3 \%)$ were misclassified. (A test of predictive accuracy with another series of cases is, of course, necessary.)

\section{TABLE II}

ANALYSIS OF FAVOURABLE AND UNFAVOURABLE CLINICAL FEATURES OF CASES FROM TABLE I

\begin{tabular}{|c|c|c|c|}
\hline 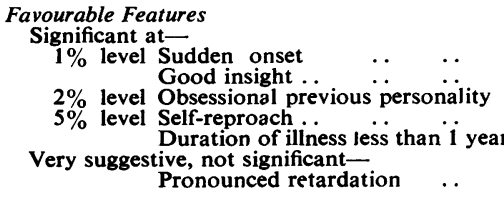 & $\begin{array}{l}\cdots \\
\cdots \\
\therefore\end{array}$ & $\begin{array}{l}\cdots \\
\cdots \\
\cdots \\
\cdots \\
\end{array}$ & $\begin{array}{l}\text { Phi Co- } \\
\text { efficient } \\
+0.31 \\
+0.24 \\
+0.21 \\
+0.20 \\
+0.19 \\
+0.14\end{array}$ \\
\hline 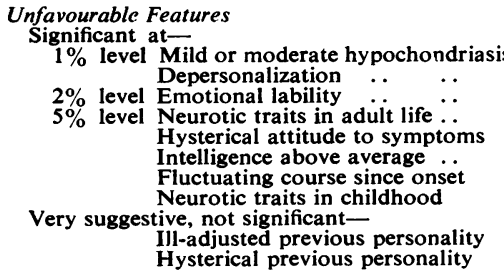 & $\begin{array}{l}\mathbf{s} \\
\ldots \\
\ldots \\
\ldots \\
\ldots \\
\ldots \\
\ldots \\
\ldots\end{array}$ & $\begin{array}{l}\ldots \\
\ldots \\
\ldots \\
\ldots \\
\ldots \\
\cdots \\
\ldots \\
\cdots\end{array}$ & $\begin{array}{l}-0.24 \\
-0.24 \\
-0.21 \\
-0.19 \\
-0.19 \\
-0.19 \\
-0.18 \\
-0.17 \\
-0.16 \\
-0.16\end{array}$ \\
\hline $\begin{array}{l}\text { 1ggestive (frequencies too small for Phi Coeffic } \\
\text { Affective incongruity } \\
\text { Irrelevance in speech } \\
\text { Hallucinations } \\
\text { Hypochondriacal previous person }\end{array}$ & & & \\
\hline
\end{tabular}

TABLE III

SCORING OF CLINICAL ITEMS IN RELATION TO EFFECTS OF TREATMENT

\begin{tabular}{c|c|c|c|c|c|c|c|c|c|c|c|c|c|c|c|c|c}
\hline $\begin{array}{c}\text { Grade of Clinical } \\
\text { Improvement }\end{array}$ & \multicolumn{10}{|c}{ Score } \\
\cline { 2 - 6 } & 0 & 1 & 2 & 3 & 4 & 5 & 6 & 7 & 8 & 9 & 10 & 11 & 12 & 13 & 14 & 15 \\
\hline B (poor). No. of cases & 0 & 0 & 0 & 1 & 4 & 4 & 7 & 3 & 9 & 8 & 5 & 2 & 4 & 1 & 1 & 0 \\
A (good). No. of cases & 0 & 1 & 5 & 14 & 17 & 15 & 11 & 7 & 5 & 0 & 3 & 0 & 0 & 0 & 0 & 0 \\
\hline
\end{tabular}

In Table IV are set out the frequencies in the improvement groups of 42 more important clinical items. In this table percentages refer to the proportion of the total cases in clinical groups A or B that showed a particular feature. For example,

TABLE IV

ANALYSIS OF CLINICAL ITEMS IN RELATION TO PROGNOSIS

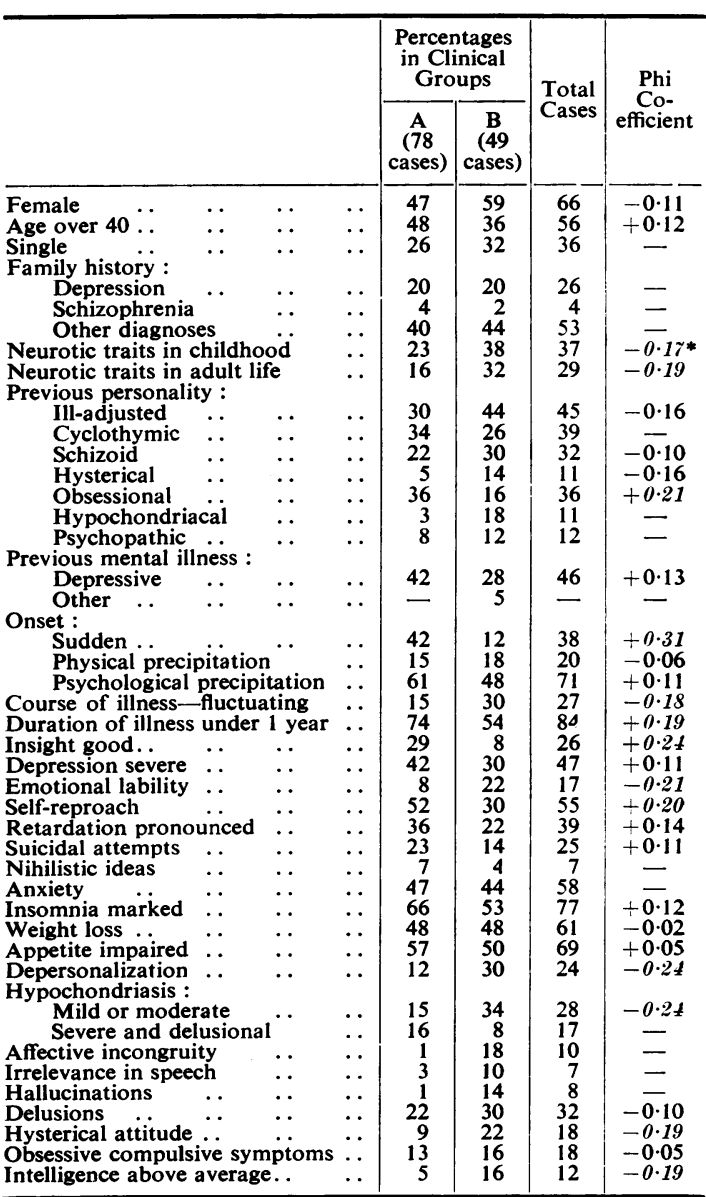

*Italicized figures indicate a significant variation. 
37 of the 127 cases showed evidence of neurotic traits in childhood. Eighteen (49\%) of the 37 were classified in Group A. Of the total 127 cases, 78 fell into Group A and of these $18(23 \%)$ had shown neurotic traits in childhood. The latter percentage reveals more accurately the association between improvement and the presence of the item.

A detailed analysis of each clinical item was undertaken but, in this context, mention will be made only of some features of interest in regard to the significant items-obsessional personality, emotional lability, depersonalization, and intelligence level.

The presence of an obsessional previous personality was a significantly favourable feature. There was a correlation between this type of personality and older age; of 71 cases aged 40 or below, $21 \%$ had obsessional personalities compared with $38 \%$ of 56 cases above this age. The obsessional personality has been described as a feature of the so-called "involutional depression". Ten cases $(28 \%)$ with this diagnosis occurred in this personality group, a higher proportion than in the series as a whole ( 21 cases or $17 \%$ ). This diagnosis is usually reserved for depressions first appearing in later life but two of the cases diagnosed here as " involutional depression" had had previous attacks. The eight cases with no previous illnesses, an obsessional personality, and onset of depression over the age of 40, did not show any favourable trend, five falling into Group A and three into Group B. There was thus no evidence that the possession of an obsessional personality was favourable only in such a setting. In fact, those cases with a history of a previous illness had a better outcome than those without. The numbers were small for statistical validity but suggested that the possession of an obsessional personality was not only favourable in the depressions of later life. When obsessional personality was associated with good insight there was a strikingly favourable outcome. Out of 10 such cases, nine were completely symptom free. The other case was diagnosed as schizophrenia and possessed features later shown to be unfavourable.

Emotional lability was associated in this series with neurotic personality traits and an hysterical attitude to symptoms. With one exception some of these factors were present in all cases not socially recovered and this association appeared to account for the unfavourable outcome.

A rough and arbitrary division was made into mild and severe depersonalization, depending upon the degree to which personality was felt to be lost or changed, and upon the distress caused to the patient.
In all but two cases the depersonalization occurred in a setting of moderate or severe depression. In 12 cases $(50 \%)$ the symptom of depersonalization remained unchanged, although in five there was improvement in other spheres, particularly in the depressive affect. "Severe" symptoms dominated this group (nine cases). In the remaining instances, there was some improvement in the symptom in one case and in the others it cleared up. These were mainly mild feelings of unreality accompanying the affective disturbance, but in three instances they were severe.

In some cases psychometric investigations had been carried out to estimate intelligence, but in many no accurate estimations were made and the intelligence level was roughly assessed from school and work records with the help of simple tests of memory, comprehension, arithmetical ability, and general knowledge. Thus the interesting negative association of high intelligence with social recovery was not beyond question. The positive association of intelligence below average was less marked, but the figures, however questionable, were sufficiently striking to warrant further investigation.

\section{Discussion}

The investigation of trends in a restricted group is an approach with necessary limitations, being concerned only with general tendencies and utilizing artificially created items. In this investigation, clinical features were considered in isolation, the interplay between them and their varying significance in different settings being neglected. The practical value of the analysis is suggested by the scoring method of predicting outcome, which was surprisingly accurate for this series (79\%). It is not suggested, however, that prognosis can be a matter of arithmetic, and no hope was entertained that an infallible guide would be provided. The contingent variables in a clinical problem are not additive, as might be suggested by this presentation. Clinical assessment must always be adapted to meet the needs of an individual case, but, though the results of this investigation cannot be conclusively applied to any one patient, they can be of practical assistance in the formulation, treatment, and prognosis by indicating the significance of certain features.

The validity of the associations for the sample, i.e., cases admitted to the Maudsley Hospital, is dependent upon possible errors due to the unreliability of observation, the inexactitude of verbal formulations, lack of objective criteria, and the influence of other therapeutic aids. Efforts were made to construct unambiguous definitions in operative terms, but complete objectivity was 
possible only in the case of such items as age, sex, civil state, and details of treatment. In regard to other items a relative reliability was possible, being greater in regard to symptoms than to the history of the present illness, previous illness, personality, and family history, and there must be doubt in regard to the items "hysterical attitude to symptoms" and "intelligence above average" because of the lack of precise criteria and adequate objective tests. It is considered that definite conclusions can be drawn in regard to associations significant at the $1 \%$ or $2 \%$ level and significance at the $5 \%$ level is sufficiently striking to be of practical clinical value.

There were many variable influences in treatment apart from the convulsive therapy, such as social therapy, occupational therapy, sedation, and personal contact with doctors and nurses but these were random influences and hence were ignored. The "immediate" improvement was recorded two weeks after treatment, which was seldom given before the patient had been in hospital some weeks without improvement. Hence the clinical change recorded was likely to be connected with the induced convulsions.

In the extensive literature there are many contradictions regarding the indications for, and the results of, convulsive therapy, particularly in relation to the significance of particular clinical features. Comparison of the findings of this investigation with the results and opinions of other workers is not attempted in detail here, partly for reasons of space and partly because, owing to unknown variations in sampling and definition, and lack of uniform objective criteria for classifying improvement, such comparison would be of little value. Although there are marked differences of opinion, some support can be found in the published work for all the positive findings presented here, with the exception of the items "sudden onset" and " good insight", which call for further mention.

Although the consensus of opinion is that in schizophrenia, treated by induced convulsions, a sudden onset of the illness is a favourable feature, there has been little discussion of this feature in illnesses particularly characterized by depression. The sample investigated here was largely comprised of cases diagnosed as "depression" and, setting aside the unreliability of information, it is difficult to account for the highly significant result regarding suddenness of onset in the absence of any support from other writers. It may be that the criteria of " acuteness" with a maximum of eight weeks was longer than in most studies. The only criterion discovered in other papers is that of four weeks given by Huston and Locher (1948a and b). It may be, however, that this factor has not before been carefully studied on a sufficiently large group of cases.

The strikingly favourable results in cases with good insight have no parallels in the literature. Gordon (1946) mentioned the poor outcome in cases with impaired judgment and insight, but no other similar references have been found. Kalinowsky (1944 and 1948) considered that, for all psychotics, the greater the loss of contact with reality the better the prognosis, and he described poor results in cases with well preserved personalities. It is not clear what was meant by a "well preserved personality" but it is likely that it implied preservation of judgment and insight. A severe psychotic illness is not necessarily associated with loss of insight, however. Lewis (1934) found that in 61 cases of melancholia, insight was good in 14 and fair in 18, and he quoted Lange's statement that a more or less obscure awareness of illness was rarely absent even in the severest melancholia, and sometimes in the presence of paranoid delusions. In this series described, delusions were present in three cases with good insight.

It is of interest to compare the indications oft prognosis suggested by this investigation with those put forward for cases, particularly suffering from? $z$ depression, not treated by convulsive therapy? Lewis (1936a), however, pointed out that in regard to " melancholia" there were no unequivocal prog? nostic signs, either as to the duration of the curren attack or as to the subsequent history, and suggested that a study of the case as a whole was of more value than attention to details commonly stressed. A full review of the literature cannot be attempted and, while recognizing the danger of misrepresentation by over-simplification, a few points of special relevance will be discussed.

An attempt was made to discover prognostic factors in depression by a survey of some of the more important papers on this subject (Paskind, 1931 ; Lewis and Hubbard, 1931 ; Strecker, Appel, Eyman, Farr, LaMar, Palmer, and Smith, 1931; Steen, 1933 ; Lewis, 1936b, 1946 ; Anderson, 1936 ; Palmer and Sherman, 1938 ; Rennie, 1942 ; Drobnes, 1943 ; Lundquist, 1945 ; Malamud, Sands, Malamud, and Powers, 1949 ; Le Mappian, 1949). There were many contradictory contentions but it was possible to find much common ground.

A family history of mental illness, age, and the occurrence of previous illnesses were of doubtful significance, though the occurrence of schizophrenia or eccentricity amongst relatives, and the onset of illness at an older age tended to be unfavourable. 
An ill-adjusted personality presaged a poor outcome, especially if there was neurotic instability or hypochondriasis. Obsessional traits were regarded as being either of no significance or unfavourable. A favourable outcome was associated with a short illness, in which the onset had been sudden and precipitated by exogenic factors no longer active. Symptoms carrying a bad prognosis were mild depression, anxiety, depersonalization, nihilistic delusions, hysterical, and schizophrenic features. Most writers regarded all types of hypochondriasis as unfavourable, but Drobnes (1943) described findings similar to those of this investigation, mild hypochondriasis being a bad omen and severe bizarre somatic delusions carrying a good prognosis. In view of the absence of any reference to insight in the literature on convulsive therapy, it is of interest to note that Lewis (1936a) pointed out that denial of mental illness by the patient was often associated with a bad outcome, as in this series.

From this discussion it can be hazarded that, although in general prognostic indications with and without convulsive therapy appear to be similar, there do seem to be differences, particularly in regard to higher age groups with depressive symptoms and previous obsessional personality. Huston and Locher (1948a) compared treated and control groups of manic depressive cases and found that whereas in the control group there was a longer illness in the older age group when there were more severe symptoms, atypical features, and psychogenic onset, these findings were not applicable to the group given shock treatment.

\section{Definitions}

Family History.-The "family" included all blood relatives of four generations. There was often a lack of detailed, first-hand information in regard to psychological illness amongst relatives, and the diagnostic categories were thus, of necessity, inexact, no attempt being made to define the terms rigidly.

Neurotic Traits in Childhood.-The history of childhood behaviour included evidence of features such as temper tantrums, night terrors, enuresis, undue fearfulness, sleep-walking, stammering, nail-biting, or thumb-sucking. If three or more of these traits had been present, or any one to an extreme degree, the item was recorded as positive.

Neurotic Traits in Adult Life.-Manifestations of abnormal psychological reactions not amounting to definite illness, i.e., not necessitating treatment. Such traits were undue anxiety, timidity, specific fears, nightmares, food fads, and hypochondriacal worries. Any of these present to a marked degree qualified the patient for inclusion in this group.
Ill-adjusted Personality.-A person poorly adjusted in the sphere of work or social relationships: frequent changes of occupation and failures in marriage or friendships, due to emotional reasons, were the main factors considered. Evidence of discharge from work because of instability, frequent absenteeism, many changes of job, and fluctuation of wage-earning capacity, were all of importance.

Previous Personality.-Combinations of traits were investigated under headings of personality "types", using well-known psychiatric terms, cyclothymic, schizoid, hysterical, obsessional, hypochondriacal, and psychopathic. In some cases, however, the terms were used in a more restricted sense than is customary. The " cyclothymic" group included persons who showed exaggerated affective reactions. In all these cases there was evidence of periods of gloominess, despondency, and pessimism, with or without irritability, all in the absence of an adequate exciting cause. The affective response was characteristically labile and the unhappy moods were usually, but not invariably, separated by intervals of normality or undue cheerfulness. "Schizoid" personalities were those in which there was evidence of difficulty in achieving normal emotional contacts with other people, their behaviour suggesting a valuation of inner experience greater than that of outer objects or people. They were "shut in ", dreamy, sensitive people, often eccentric, all with difficulties in personal relationships revealed by shy, reclusive behaviour. Persons were classified as " hysterical" if they were unduly responsive to the situation, especially if by their excessive response they could fulfil wishes of which they were hardly aware or evade what was painful in the situation (Lewis, 1946). Their actions suggested an over-valuation of, and overindulgence in, phantasy, and showed the tendency to form personal relationships of a fleeting, superficial nature, and to behave histrionically. "Obsessional " personality was a grouping characterized by rigidity of behaviour patterns, the members being characteristically conscientious, scrupulous, clean and tidy to an extreme degree, either obstinate or submissive, and commonly troubled by doubts. Many showed minor obsessional traits such as unnecessary compulsive checking, counting, or touching, which were not complained of by the patient and did not interfere with his activities sufficiently to be classed as symptoms. Not all of these traits were present in each case but always there was the felt need for rigidity and order in some important aspect of life. A " hypochondriacal" person paid " a continuous attention to (his) state of health with or without the tendency to ascribe a disease to himself from insignificant signs" (Bleuler, 1924). There was a persisting "body awareness" not amounting to hypochondriasis, as defined later. "Psychopathic personality" was here used in a restricted sense being limited to "sociopathic personalities" (Curran and Mallinson, 1944) including inadequate people with shallow, changing, emotional reactions and a poverty of will-power and determination, the aggressive, explosive, amoral and often delinquent persons, and those eccentrics whose odd behaviour 
brought them into conflict with society. These cases constituted in fact an extreme section of the ill-adjusted personalities.

Sudden Onset.-A rapid deterioration to the condition on admission, occurring within the space of eight weeks.

Physical Precipitation.-Organic illness or injury was associated with the onset of the mental disturbance. Such physical factors included febrile colds, tropical diseases, bronchitis, and loss of a leg.

Psychological Precipitation.-The onset of the illness was associated with psychological stress occasioned by disturbance in the environment. These disturbances, such as bereavement, marital problems, and difficulties at work, would have caused distress to a normal person but here led to an extreme reaction, manifest in illness.

Insight.-The capacity of a patient to understand the nature of his iliness : good insight implied a recognition of the "mental" or " psychological" quality, with some understanding of the more obvious factors in the causation.

Emotional Lability.-Rapid changes of mood occurring within the space of a few hours.

Self-reproach.-A falsely derogatory self-estimate, with self-blame, especially in regard to abilities or moral qualities.

Retardation.-Difficulty in thinking to an end and in initiating action, as manifest in talk and other behaviour.

Suicidal Attempts.-Efforts to injure the self in such a way that the subject might have expected death to ensue. In the distinction between histrionic behaviour and suicidal attempts, factors such as method, persistence, intelligence, were considered. Doubtful cases were here classed as being genuine.

Nihilistic Ideas.-Negation of the self or a part of the body.

Anxiety.-A subjective state of " expectation but not certainty of something unpleasant happening" (Lewis, 1936a) accompanied by objective signs such as tenseness of the musculature, perspiration, tremor, tachycardia, and restless movements. In this investigation the presence of such objective evidence was a sine qua non. Agitation, commonly described separately, was here included under the heading of anxiety.

Depersonalization.-The expression by a patient of a feeling of change in his relationship, as a person, to the outer world, as compared with a former state. This change was experienced as being either in himself or in the objects around him. All feelings of unreality were included under this head.

Hypochondriasis.- " Physically unjustified or exaggerated bodily complaints" (Brown, 1936) : an extreme form of the hypochondriacal personality trait defined earlier, distinguished by the fact that it was a feature of an illness, that caused a definite interference with a person's activities and well-being. The symptom either had not been present before the onset of the illness, or only in a much milder form. Three degrees of severity were recognized, varying from anxious preoccupation with, and over-concern about, body sensations experienced by "normal" people (mild), to belief in the existence of a physical illness (moderate), and settled conviction of gross physical illness usually incurable (severe).

Affective Incongruity.-Evidence of an emotional response not in keeping with the circumstances or topic of conversation.

Irrelevance in Speech.-A neglect of the usual logical sequences, occasioned by no external stimulus. In conversation topics were changed without any apparent meaningful connexion.

Hallucinations.-False perceptions related to auditory, olfactory, or visual senses. In a few cases it was difficult to assess whether sensations described were hallucinations, illusions, or vivid mental images. If there was any doubt the item was recorded as being negative.

Delusions.-Beliefs not justified by direct reference to the facts and not shakable by reason : hypochondriaca delusions were not included here as they came under the heading of hypochondriasis. The delusional ideas? varied from misinterpretations of happenings in the environment, and attribution to such happenings a special reference to the subject, to beliefs of being influenced preternaturally, and paranoid delusions with a logically consistent system based on false premises.

Hysterical Attitude.-Symptoms, physical or psycho logical, associated with an excessive emotional response by which unconscious wishes were fulfilled or unpleasantness avoided. It was associated in almost all cases with hysterical personality traits and other psychoneurotic features. It was difficult to assess such reactions unequivocally and the accuracy of the figures was in doubt.

Obsessive Compulsive Symptoms.-A subjective experience of compulsion in regard to thought or action which was resisted by the patient, as being foreign to his personality.

\section{Summary}

An investigation was carried out in an attempt to establish more precise indications for convulsive therapy by means of a statistical assessment of the significance of individual clinical features in regard to the immediate outcome of treatment.

One hundred and fifty unselected cases were studied but, as there was reason to assume that treatment had been inadequate in some, 127 only were chosen for detailed analysis.

Statistical methods were employed to estimate 
the degree of association between the immediate results of treatment and 121 defined items relating to age, sex, heredity, previous history, mental status, and features of the therapy. Significant or very suggestive associations were found in regard to 20 such items. A scoring method designed to predict the outcome of treatment was reasonably accurate for this series, only $21 \%$ of cases being misclassified.

A comparison was made between the findings and prognostic indications that have been suggested in regard to depressive illnesses not treated by convulsive therapy. A general correspondence was found though there were differences regarding the significance of age and obsessional traits in the previous personality.

This article has been abstracted from a thesis for the degree of M.D. at the University of Cambridge. My thanks are due to Mr. Jonckheere and Dr. S. Crown for assistance in the use of statistical methods, and to Professor A. J. Lewis and Dr. H. J. Eysenck for valuable advice and criticism.

\section{REFERENCES}

Anderson, E. W. (1936). J. ment. Sci., 82, 559

Bleuler, E. (1924). Textbook of Psychiatrv. Macmillan, New York.

Brown, F. (1936). J. ment. Sci., 82, 295.

Curran, D., and Mallinson, P. (1944). Ibid. 90, 266.

Drobnes, S. (1943). Amer. J. Psychiat. 99, 818

Gordon, H. L. (1946). New York St. J. Med., 46, 407.

Guildford, J. P. (1941). Psychometrika, 6, 1.

Huston, P. E., and Locher, L. M. (1948a).'Arch. Neurol. Psychiat. Chicago, 59, 385

Kalinowsk, (1948b). Ibid. 60, 37.

. Bull. N.Y. Acad. Med., 20, 485

(1948). In Failures in Psychiatric Treatment, ed. Hoch, P. H. p. 161. Grune and Stratton, New York.

Le Mappian, M. (1949). Encéphale, 38, 220.

Lewis, A. J. (1934). J. ment. Sci., 80, 277.

(1936a). Ibid. 82, 488 .

(1936b). Lancet, 2, 997.

(1946). "Psychological Medicine". In A Textbook of the Practice of Medicine, ed. Price, F. W., 7th ed. Oxford University Press, London.

Lewis, N. D. C., and Hubbard, L. D. (1931). Ass. Res. nerv. ment. Dis., 11, 539 .

Lundquist, G.'(1945). Acta psychiat. Kbh. Suppl., 35.

Malamud, W., Sands, S. L., Malamud, I. T., and Powers, P. J. P. (1949). Amer. J. Psychiat., 105, 567.

Palmer, H. D., and Sherman, S. H. (1938). Arch. Neurol. Psychiat. Chicago, 40, 762 .

Paskind, H. A. (1931). Ibid., 25, 145 .

Rennie, T. A. C. (1942). Amer. J. Psychiat. 98, 801.

Steen, R. R. (1933). Psychiat. Quart., 7, 419.

Strecker, E. A., Appel, K. E., Eyman, E. V., Farr, C. B., LaMar, N. C., Palmer, H. D., and Smith, L. H. (1931). A research nerv. ment. Dis. Proc., 11, 471.

\section{THE AUGUST (1953) ISSUE}

The August (1953) issue contains the following papers :-

Tumours of the Glomus Jugulare. By R. A. Henson, J. V. Crawford, and J. B. Cavanagh.

The Pathological Report of a Case of Phenylpyruvic Oligophrenia. By J. A. N. Corsellis.

Nervous Discharge from Small Painless Lesions in Skin and Muscle. By P. W. Nathan.

The Examination of the Cerebrospinal Fluid and Cerebral Cyst Fluid by Paper Strip Electrophoresis. By J. N. Cumings. The Early Diagnosis of Tumours of the Cauda Equina. By John N. Milnes.

Nocturnal Myoclonus. By Charles P. Symonds.

Familial Hemiplegic Migraine. By C. W. M. Whitty.

Periodic Paralysis. By Edwin R. Bickerstaff.

Ribosuria in Muscular Dystrophy. By W. B. Matthews and M. J. H. Smith.

Personality Changes After Operations on the Cingulate Gyrus in Man. By P. MacDonald Tow and C. W. M. Whitty.

Photo-metrazol Sensitivity in Catatonic Schizophrenia. By D. M. Leiberman and J. Hoenig.

Electromyographic Studies of Emotional States in Normal Subjects. By P. P. Newman.

A number of copies are still available and may be obtained from the Publishing Manager, British Medical Association, Tavistock Square, W.C.1, price 12s. 6d. 